\title{
Wireless Communications Mode of Support Reaction Test System for Aerial Work Platform
}

\author{
Zhi-Xin LIU ${ }^{1, a}$, Xiang-Chun NIU1 ${ }^{1}$, Sheng-Hua QIAO ${ }^{1}$ \\ ${ }^{1}$ China Automotive Technology \& Research Center, Tianjin, 300162, China
}

Keywords: Wireless communications, Support reaction test system, Aerial work platform.

\begin{abstract}
The measuring and monitoring of the support reaction of the aerial work platform is an important method to prevent its overturn. In view of the fact that the turntable is in a rotational movement during the whole process, it is easy to cause the tangling of the signal cable if using the traditional wired measuring method, which often results in the problem of signal interruption. Therefore, this paper develops a test system of support reaction based on wireless communications. In order to solve the problems of interference or occupation of wireless communications frequency and power supply of measuring equipment, a frequency transfer method is adopted to avoid these problems. With the lithium-ion battery used as the power supply, the design of regulator voltage circuit helps solve the problem of power supply for measuring equipment. Test results show that measuring equipment has stable and reliable wireless communications with the outside world.
\end{abstract}

\section{Introduction}

In recent years, construction projects are on the increase and with it come the increased accidents of the hydraulic aerial cage truck, especially the tipping accidents, which account for a large proportion. They result in car crash and cause damaging secondary disasters. One of the main reasons lies in the product design. It is deeply rooted in the lack of quantitative stability standard of the hydraulic aerial cage truck in China. More often, the contact state of the support reaction and ground is considered as the condition to determine the stability situation of the aerial platform. In view of the fact that the support reaction of aerial platform is closely related to its stability, the accurate measuring and monitoring of outrigger reaction can not only prevent the occurrence of tipping accidents, but also solve the existing problem of the lack of test methods for requirements of aerial platform.

Considering the fact that the turntable is in a rotational movement during the whole process, it is easy to cause the tangling of the signal cable if using the traditional wired measuring method, which often results in the problem of signal interruption. Therefore, this paper develops a test system of outrigger reaction based on wireless communications. In order to solve the problems of interference or occupation of wireless communications frequency and power supply of measuring equipment, a frequency transfer method is adopted to avoid these problems. With the lithium-ion battery used as the power supply, the design of regulator voltage circuit helps solve the problem of power supply for measuring equipment.

\section{Measurement System of Support Reaction}

The measurement system of support reaction of hydraulic aerial cage truck is composed of a hardware system for acquiring measurement data and a data processing software system. As is shown in Figure 1, the hardware system consists of the industrial control computer, the measuring devices of the rotary angle, the tilt angle, and the load. Among them, the function of the measuring device of the rotary angle is to measure the rotation angle of the platform plane; the function of the measuring device of tilt angle is to measure the inclination angle of the support arm; the function of the measuring device of load is to measure the supporting reaction of the supporting leg. All these three devices mainly make acquisition of parameters and transmit data to the industrial computer, and the data processing software system displays the text and graphic of various parameters through the user interface of the industrial computer. 


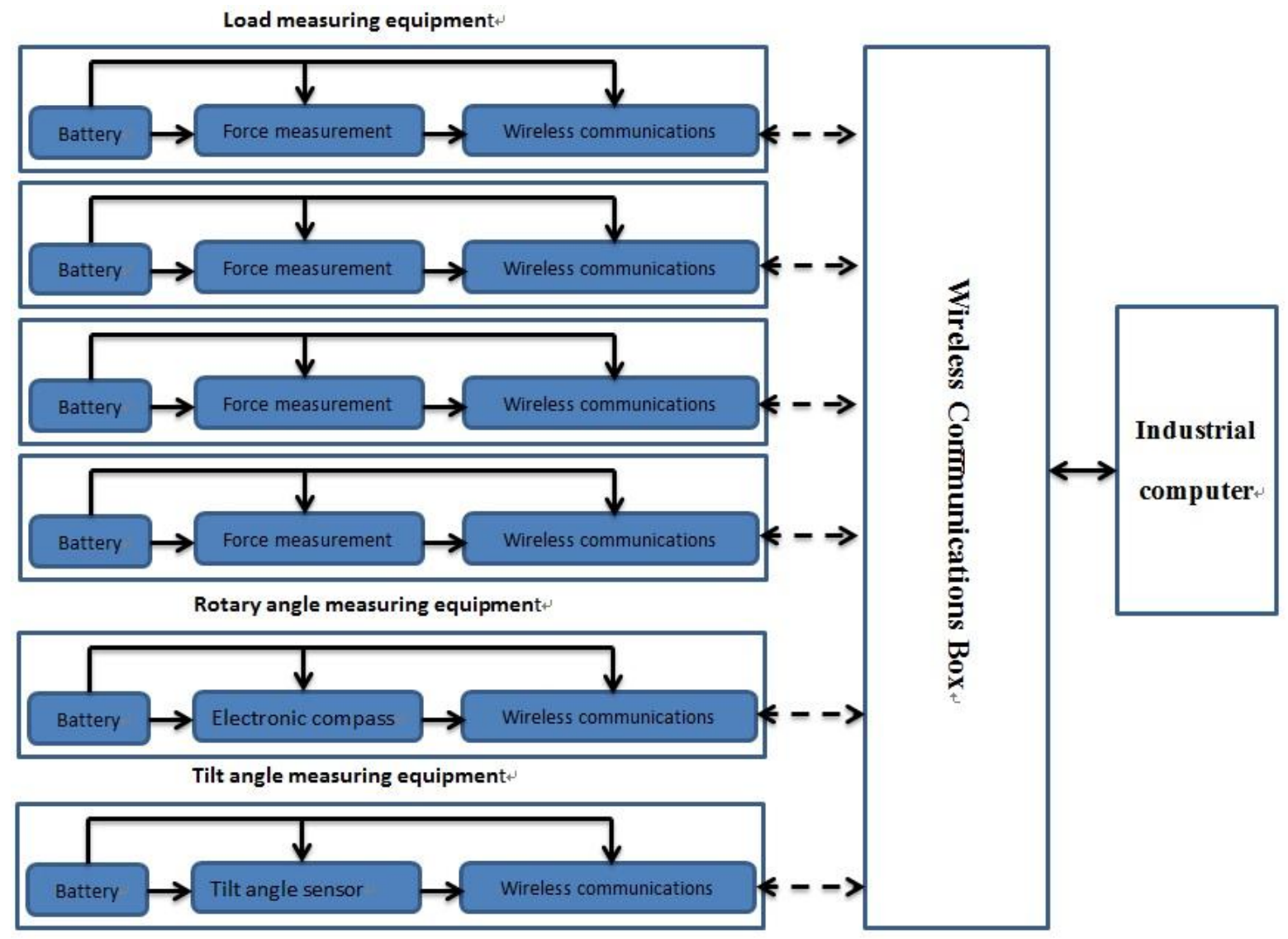

Figure1. Measurement system of the reaction of supporting leg

The measuring devices are connected to the industrial computer wirelessly, which not only saves the connection cable, but also does not affect the normal operation of the measured vehicle after the measuring device is installed on the tested vehicle. Just fix them in the appropriate location and it is done. At the same time, there is no restriction on the rotation of the platform support arm on the aerial working platform, which can guarantee the smooth measurement of data.

\section{Wireless Design of System}

As the measuring devices are connected to the industrial computer wirelessly, there are two problems that need to be solved, that is, the interference of wireless data communications between the measuring devices and the industrial computer and power supply for these devices.

\section{Wireless Data Communications}

There are several types of wireless communications: Wi-Fi, Bluetooth, Zigbee, and radio frequency (RF) technologies. Table 1 lists the advantages and disadvantages of various wireless communications [1-3].

Domestically, the wireless communications frequency is mainly of $2.4 \mathrm{GHz}$, and meanwhile the ISM band is the only available in the $2.4 \mathrm{GHz}$ band. Anyone can use this spectrum free. $2.4 \mathrm{GHz}$ band wireless systems include Bluetooth, WiFi, wireless USB, zigBee, as well as cordless phones, microwave ovens and medical equipment, etc. As ISM-2.4GHz band is extensively used, it is too crowded with increasingly prominent wireless interference and electromagnetic compatibility problems. Now a large number of RF chips can be used for wireless data transmission. It is relatively simple and easy to develop. Compared with Bluetooth, WiFi, zigBee and other technologies, radio frequency technology has the flexibility of choosing the wireless communications frequency, which can avoid the interference of wireless communications equipment outside. 
Table 1. Comparisions of various wireless communications

\begin{tabular}{|c|c|c|c|}
\hline Type & Frequency & Advantages & Disadvantages \\
\hline Wi-Fi & $2.4 \mathrm{GHz}$ ISM & $\begin{array}{c}\text { automatic adjustment of bandwidth and } \\
\text { effective protection of the network } \\
\text { stability and reliability }\end{array}$ & $\begin{array}{c}\text { Mainly used in wireless } \\
\text { broadband network }\end{array}$ \\
\hline $\begin{array}{c}\text { Blue } \\
\text { tooth }\end{array}$ & $2.4 \mathrm{GHz}$ ISM & $\begin{array}{c}\text { Convenient, flexible and safe, low cost, } \\
\text { low power consumption }\end{array}$ & $\begin{array}{c}\text { Short communications } \\
\text { distance, less than 10 meters }\end{array}$ \\
\hline Zigbee & $2.4 \mathrm{GHz}$ ISM & $\begin{array}{c}\text { Low power, low cost, low speed, short } \\
\text { distance, short delay, high capacity, high } \\
\text { security }\end{array}$ & $\begin{array}{c}\text { Short communications } \\
\text { distance, less than 75 meters }\end{array}$ \\
\hline $\mathrm{UWB}$ & $3.1-10.6 \mathrm{GHz}$ & $\begin{array}{c}\text { Anti-interference, high transmission rate, } \\
\text { huge capacity }\end{array}$ & $\begin{array}{c}\text { Effective transmission } \\
\text { distance within 10m }\end{array}$ \\
\hline $\mathrm{RF}$ & $300 \mathrm{KHz} 30 \mathrm{GHz}$ & $\begin{array}{c}\text { Anti-interference, long transmission } \\
\text { distance }\end{array}$ & $\begin{array}{c}\text { customized communications } \\
\text { protocol required }\end{array}$ \\
\hline
\end{tabular}

\section{Selection of Wireless Communications Chip}

Currently many kinds of wireless chips on the market, and the main manufacturers include Silicon Labs from the United States, Nordic and Chipcon from Norway. In view of the fact that Si4431 chip has the characteristics of high integration, low cost, great flexibility, simple peripheral and easy design, this paper uses Si4431 chip with Silicon Labs. Its continuous frequency coverage ranges from $240 \mathrm{Mhz}-930 \mathrm{Mhz}$, with the output power of $+20 \mathrm{dbm}(100 \mathrm{~mW})$ and the receiving sensitivity of-116dbm. The chip contains a high-performance ADC. It completes filtering, demodulating, packet processing in the receive path and digital modem, making it very suitable for configuring a number of applications [4].

The circuit of the connection of wireless communications chip with microcontroller is shown in Figure 2. The microcontroller receives the data sent out by the measuring unit through the serial port and sends the processed data to Si4431 through the SPI serial port. Before transmitting the data via the antenna, Si4431 processes the data by adding the preamble, the synchronization word, the data payload length, the pilot code internally and CRC check. Finally, the correct data are sent to the microcontroller through the serial port.

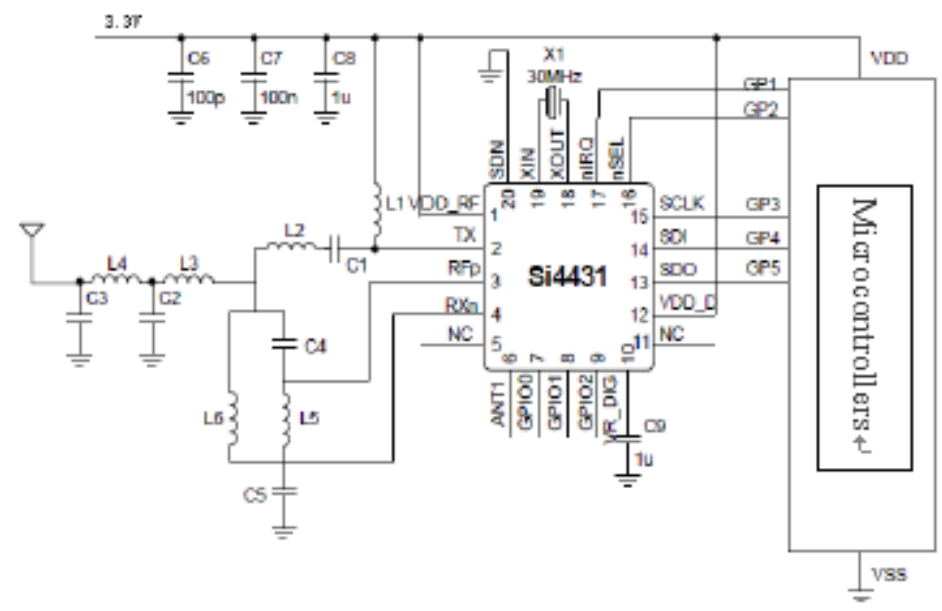

Figure 2. Circuit of the connection of Si4431 with single chip

\section{Frequency Transfer Solution based on Wireless Interference}

In practical situations, it is possible that the occupied frequency of communications or a great amount of interference make it unable to receive correct data. Consequently, the wireless communications module should has the feature of dynamically changing the communications frequency to avoid the occupied or interfered frequency. The wireless communications equipment is expected to fulfil the following functions: When the communications are seriously disturbed, it is 
able to move the communications frequency to the channel without interference. Otherwise, it should maintain the operation on the original channel.

In this design, each measuring device is reserved 9 communications frequencies with the interval of 3 times of frequency deviation in addition to the normal communications frequency. When wireless communications devices and the measuring equipment encounter external interference and cannot receive the normal communications data 5 times in a row, the wireless communications device changes the communications frequency at $10 \mathrm{~ms}$ interval and sends out the communications data package, while waiting for the response signal of the measuring equipment. If no response signals are received from the measuring equipment in $10 \mathrm{~ms}$, the communications frequency is shifted to the next reserved communications frequency, and the communications data is retransmitted. If a response signal is received from the measuring equipment at the new communications frequency, it means there is no interference at that communications frequency. When the measuring equipment fails to receive data from the wireless communications device within $50 \mathrm{~ms}$, the communications frequency is changed at an interval of $100 \mathrm{~ms}$. If the measuring equipment has not received communications package transmitted from the wireless communications device in $100 \mathrm{~ms}$, the communications frequency is set to the next reserved frequency.

Whether the transmitter and receiver are synchronized or not, the measuring equipment should ensure the frequency of the wireless communications device is the same as the transmission and reception frequency in $10 \mathrm{~ms}$ of the $100 \mathrm{~ms}$ period in a certain channel to complete the transmission and reception of one frame of data. If the transceiver data is detected normally, the system keeps working in the channel and goes into in the normal communications phase. If the transceiver data detection is unsuccessful, the receiver will go to the next channel to continue the detection until it is successful. Therefore, in this way, even some serious random interference occurs during the measuring process, the wireless communications device and the measuring device can find the uninterrupted communications frequency within $1 \mathrm{~s}$ to continue the data transmission without stopping the measurement and changing the communications frequency.

\section{Power Supply Scheme}

Table 2. Advantages and Disadvantages of batteries

\begin{tabular}{|l|l|l|l|}
\hline \multicolumn{1}{|c|}{ Type } & Votage & \multicolumn{1}{c|}{ Features } & \multicolumn{1}{c|}{ Disadvantages } \\
\hline NiMH battery & $1.2 \mathrm{~V}$ & $\begin{array}{l}\text { strong anti-overcharge and } \\
\text { discharge capacity, good low } \\
\text { temperature performance and } \\
\text { high power density }\end{array}$ & $\begin{array}{l}\text { high self-discharge rate, } \\
\text { poor high temperature performance, } \\
\text { Exhaust gases during overcharge and } \\
\text { overdischarge }\end{array}$ \\
\hline $\begin{array}{l}\text { Lithium Ion } \\
\text { Battery }\end{array}$ & $3.7 \mathrm{~V}$ & $\begin{array}{l}\text { high energy density low self- } \\
\text { discharge }\end{array}$ & $\begin{array}{l}\text { high price and low numbers of charge } \\
\text { and discharge }\end{array}$ \\
\hline PLB Battery & $3.7 \mathrm{~V}$ & high security & $\begin{array}{l}\text { poor low temperature performance and } \\
\text { liable to expansion }\end{array}$ \\
\hline ALB battery & $3.7 \mathrm{~V}$ & $\begin{array}{l}\text { excellent low temperature } \\
\text { characteristics }\end{array}$ & electrolyte leakage \\
\hline
\end{tabular}

The measuring equipment cannot use the AC / DC power supply solution. The use of rechargeable batteries as the power supply for it is the only solution to realizing the wireless communications of the measuring equipment. There are a variety of battery solutions to choose from, including Ni-MH, Li-ion, Li-ion polymer (PLB), and Li-ion battery (ALB). Listed below are the advantages and disadvantages of some common batteries [5-7].

\section{Battery Selection}

From the perspective of cost-performance ratio, the lithium-ion battery is used as the power supply. Because the price of lithium-ion battery is much lower than the ALB, PLB battery, while the performance is better than the nickel-metal hydride batteries. Due to the existence of memory 
effect, Ni-MH battery is suitable for fully charged and fully discharged process. This is ideal for products that will often run out of electrical energy.

\section{Selection of Chips for Stable Power Supply}

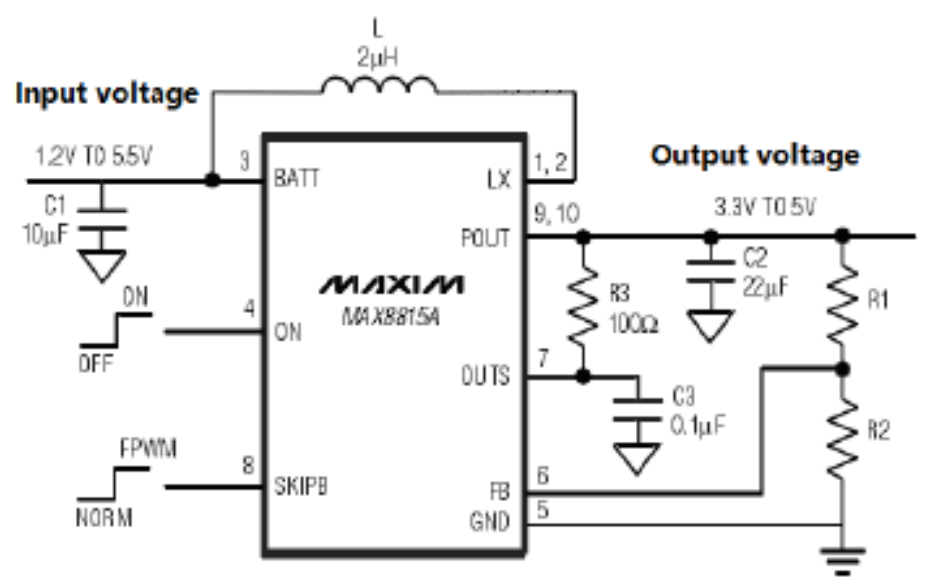

Figure 3 The external circuit of MAX8815A

The use of batteries as a power supply often suffers instability of battery output voltage. The lithium-ion battery output voltage ranges from 3.0 to $4.2 \mathrm{~V}$, with large output voltage fluctuations. However, as the system has strict power requirements, it needs to adopt a highly efficient voltage converter. This design uses the MAX8815A as a voltage converter. Its external circuit is shown in Figure 3.

The MAX8815A DC-DC Boost Converter is a highly efficient synchronous buck converter with low quiescent current, True Shutdown ${ }^{\mathrm{TM}}$ and inrush current limiting. It can works in the modes of the highest efficiency $(97 \%)$, low quiescent current $(30 \mu \mathrm{A})$ and low noise forced PWM. It is characterized by a variety of protection features such as protection of output overload and shortcircuit, suppression of inrush current during soft-start, and thermal shutdown. [8]

\section{Application results}

\section{Wireless Communications Test}

In the application test of wireless communications, three test methods are used. One is the interference from the adjacent communications channel, while the other two methods are the complete occupation of the communications frequency point to cut the wireless communications and then test whether it can return to normal. The test methods and results are as shown in Table 3.

Table 3. Interference methods and results

\begin{tabular}{|c|c|}
\hline Interference methods & Results \\
\hline $\begin{array}{c}\text { Conduct inference outside the frequency occupied by the } \\
\text { measuring equipment with the high-power wireless } \\
\text { transmitters. }\end{array}$ & $\begin{array}{c}\text { The frequency will automatically switch to } \\
\text { the pre-set communications frequency when } \\
\text { it is less than 2 times the frequency } \\
\text { deviation, and the normal communications } \\
\text { are feasible. }\end{array}$ \\
\hline $\begin{array}{c}\text { Use the high-power wireless transmitters to continuously } \\
\text { occupy the frequency of the measuring device in advance. }\end{array}$ & $\begin{array}{c}\text { Find the undisturbed pre-set communications } \\
\text { frequency pre-set and achieve normal } \\
\text { communications }\end{array}$ \\
\hline $\begin{array}{c}\text { Continuously occupy the frequency of the wireless } \\
\text { pommunications of the measuring device with the high- } \\
\text { device has found the frequency that ensures its normal } \\
\text { communications. }\end{array}$ & $\begin{array}{c}\text { Find the undisturbed pre-set communications } \\
\text { frequency pre-set and achieve normal } \\
\text { communications }\end{array}$ \\
\hline
\end{tabular}




\section{Battery Life Test}

In practical applications, the current in the normal use of the wireless communications part is less than $100 \mathrm{~mA}$ in the process of data emission and less than $30 \mathrm{~mA}$ in data reception. The current in the normal use of the measuring part is less than $60 \mathrm{~mA}$, so we use the lithium battery with $200 \mathrm{~mA}$ maximum continuous operating current, $400 \mathrm{~mA}$ maximum pulse current, and $1000 \mathrm{mAH}$ capacity. According to the theoretical calculation, the battery can work continuously for 5 hours. Tests show that the measurement system works continuously for more than seven hours. Each measurement time, from the beginning of preparation to the end of measurement, is not more than 20 minutes, and it can conduct at least 20 measurements after fully charged.

\section{Summary}

This paper develops a test system of support reaction based on wireless communications. In order to solve the problems of interference or occupation of wireless communications frequency and power supply of measuring equipment, a frequency transfer method is adopted to avoid these problems. With the lithium-ion battery used as the power supply, the design of regulator voltage circuit helps solve the problem of power supply for measuring equipment. Test results show that measuring equipment has stable and reliable wireless communications with the outside world, realizing real wireless communications.

\section{References}

1. Fu Min-cang, Feng Li-jie, Li Wen-bo. Short-range Wireless Network Communication Technology and Its Application [J]. Modern Electronics Technology, 2006,29 (11): 15-17,30.

2. Yuan Yi, Su Hong-gen. On the Application of Wireless Network based on ZigBee Technology [J]. Journal of Computer Applications and Software, 2004,21 (6): 89-91

3. Zhang Li. Near-field Wireless Communication Technology and Its Application Prospect [J]. Telecommunication Engineering, 2005, (11)

4. Silicon Laboratories.Si4431 ISM transceiver DataSheet, 2008.

5. Wang Haiming, Zheng Shengshuo, Liu Xingshun. Characteristics of Lithium-ion Battery and Its Application [J] .Electrical Age, 2004, (03).

6. Mao Guolong. Development Status of Lithium-ion Battery and Its Application Prospect [J]. China Electronic Market, 2009, (08).

7. Han Xiangyang, Zhou Fengxing, Hulei, et al. Design and Implementation of a Distance Monitoring System based on Wireless Transceiver Module nRF903 [J]. Electronic Measurement Technology, 2006, 29 (5): 187-189,198. HAN Xiang-yang, ZHOU Feng-xing, HU Lei.

Maxim Integrated Products MAX8815A datasheet

8. Maxim Integrated Products MAX8815A datasheet 